\title{
EXPERIMENTAL INVESTIGATION OF A CONTROL SYNTHETIC JET
}

\author{
Lucie NĚMCOVÁ, Jozef KORDÍK, Zdeněk TRÁVNÍČEK, Václav KOPECKÝ•
}

\begin{abstract}
Synthetic jets were used in previous studies to control a continuous round air jet. This study focuses on the single synthetic jet, which is measured using Constant Temperature Anemometry (CTA) and Particle Image Velocimetry (PIV). Velocity profiles and frequency characteristics of the single synthetic jet are discussed and the velocity maps at frequencies of $30 \mathrm{~Hz}, 81 \mathrm{~Hz}$ and $190 \mathrm{~Hz}$ are presented. Finally, velocity, flow rate and momentum coefficients featured the present flow control are evaluated, and examples of actively controlled round air jet are put on. The results confirm efficiency of the present flow control method.
\end{abstract}

\section{INTRODUCTION}

There are many technical applications in which control of free jets is needed for an aerodynamic noise reduction, lift control, and heat/mass transfer treatment. For these applications, flow control causing the enhancement of fluid mixing or transition from laminar to turbulent flow can improve the efficiency. Flow control can be carried out using passive techniques like noncircular nozzles or different tabs at the nozzle exit. Active flow control techniques include continuous control jets, acoustic excitations or synthetic jets, Gad-El-Hak [1], Fernholz [2]. Today, active flow control techniques are studied worldwide.

Synthetic jet (SJ) is generated using an oscillating element in a cavity. Fluid is sucking in and pushing out of the cavity through an orifice - Smith and Glezer [3], Cater and Soria [4]. This is a special case of pulsating flow with zero net mass flux in the actuator exit. Oscillating element could be a diaphragm or piezoelectric material. Following these characteristics we can point out the advantages of synthetic jets - it is possible to control them rather easily using an electronic system and we do not need any supply pipe. For these reasons a flow control by means of SJs can be utilized in many promising applications.

In the previous work $[5,6,11]$ the effect of control synthetic jets on a continuous (main, round) jet was studied. The primary jet at $R e=1600$ or $R e=5000$ (defined as $R e=$ $U_{0} D / v$, where $U_{0}$ is the mean velocity in the nozzle, and $D$ is the nozzle diameter - see Fig. 1(a)) was controlled using four synthetic jet actuators placed perpendicularly to the

\footnotetext{
- Lucie Němcová, Technical University of Liberec, Studentská 1402/2, 46117 Liberec 1, lucie.nemcova@tul.cz,

Jozef Kordík, Institute of Thermomechanics AS CR, Dolejškova 1402/5, 18200 Praha 8, kordik@it.cas.cz

Zdeněk Trávníček, Institute of Thermomechanics AS CR, Dolejškova 1402/5, 18200 Praha 8, tr@it.cas.cz

Václav Kopecký, Technical University of Liberec, Studentská 1402/2, 46117 Liberec 1, vaclav.kopecky@tul.cz,
}

This is an Open Access article distributed under the terms of the Creative Commons Attribution License 2.0, which permits unrestricted use, distribution, and reproduction in any medium, provided the original work is properly cited. 
main nozzle axis, at its exit; they operated at frequency of $81 \mathrm{~Hz}$ or $190 \mathrm{~Hz}$, respectively. Four different modes of excitation were investigated and described in $[5,6,11]$. Now, we focus on a single synthetic jet actuator used in previous work to describe properly its characteristics.

\section{EXPERIMENTAL SETUP}

Figure 1(a) shows the continuous round air jet (main jet) that is controlled using a system of four synthetic jet actuators. In this experiment, the synthetic jets are created by loudspeaker's membrane oscillations. Two opposite placed loudspeakers are seriesconnected and supplied by $0.02 \mathrm{~W}(0.01 \mathrm{~W}+0.01 \mathrm{~W})$. For actual experiments a quarter cut of complete jet was made. This quarter segment enables to access all areas we are interested in. Detailed geometry of single SJ actuator is shown in Figure 1(b). Scheme of this segment is displayed and coordinates are defined; $x^{* *}$ and $z^{*}$ represent the streamwise and transversal coordinates. Inclination of the flow represents coordinate $y^{*}$. At the measurements it was found that the jet deflects with angle of $11^{\circ}$ because of the generator's geometry. For that reason deflected axis $x^{*}$ was implemented.

(a)

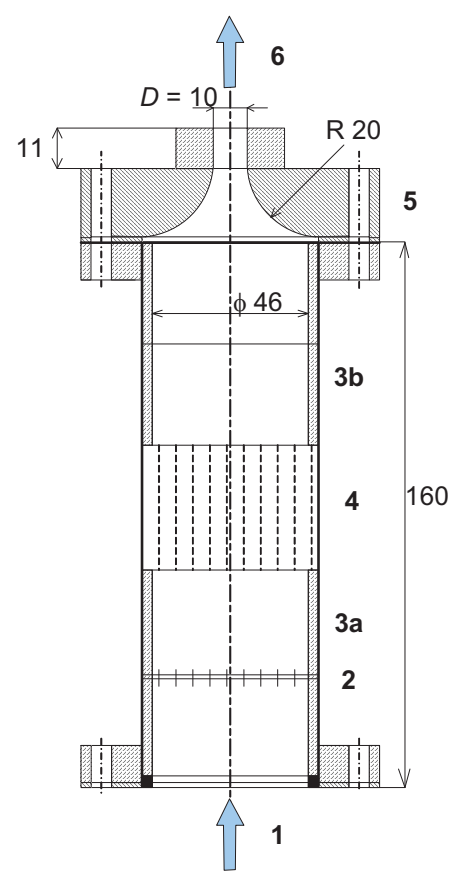

(b)
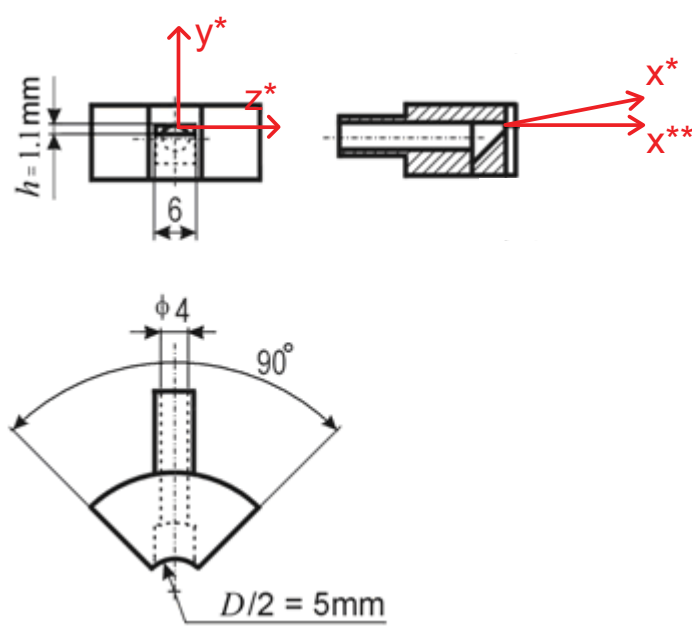

Figure 1: (a) The main, quadrant-contoured nozzle generating the main flow, with the four SJ actuators acting at its exit; 1: primary air flow supply, 2: grid, 3a, 3b: settling chambers, 4: honeycomb, 5: contoured contraction, 6: air flow investigated

(b) The SJ actuator, one of the four segments surrounding the main nozzle exit.

A controlled round air jet is defined by centerline mean velocity $U_{0}$.

$$
U_{0}=\frac{Q_{0}}{A}
$$

where $Q_{0}$ is volume flow rate at the main jet exit and $A=\pi D^{2} / 4$ is cross section of the jet exit. Although this paper is primary oriented on description of the single control jet, it is 
worth to know $U_{0}$ to evaluate the rates defined below $(3),(4)$ and (5). Equation (2) defines time-averaged S] orifice velocity [3]:

$$
U_{0 S J}=\frac{1}{T} \int_{0}^{\tau} u_{S J}(t) d t
$$

where $u_{\mathrm{SJ}}(t)$ is the velocity in SJ actuator orifice, and $\tau$ is the extrusion stroke duration. The strength of the synthetic jet (relatively to the main jet) can be quantified in terms of the ratios of the velocities, flow rates, and moments, i.e. using the velocity, flow rate and momentum coefficients, $c_{U}, c_{\mathrm{Q}}$, and $c_{\mathrm{m}}$, respectively:

$$
\begin{aligned}
& c_{U}=\frac{U_{0 S J}}{U_{0}} \\
& c_{Q}=n\left(\frac{A_{S J}}{A}\right)\left(\frac{U_{O S J}}{U_{0}}\right) \\
& c_{m}=\frac{n \bar{I}_{S J}}{\rho U_{0}^{2} A}
\end{aligned}
$$

where $A_{\mathrm{S} J}$ is the cross section area of the SJ actuator slot $(1.1 \times 6.0 \mathrm{~mm}), n$ is the number of active SJs, $A$ is the cross section area of the main round nozzle $\left(A=\pi D^{2} / 4\right), \rho$ is the working fluid density (we consider that the densities of the main jet and control SJs are identical), $\bar{I}_{S J}$ is the time-average SJ momentum (generating during the outstroke and averaging over the entire period - this consideration is similar with the definition of $U_{0 \text { s }}$ by Eq.(2) above):

$$
\bar{I}_{S J}=\frac{1}{T} \rho A_{S J} \int_{0}^{\tau} u_{S J}^{2}(t) d t
$$

Assuming the "slug (plug) flow model" (one dimensional periodic flow through the SJ actuator orifice, $\left.u_{\mathrm{SJ}}(t)\right)$ and considering the harmonic actuation $\left(u_{\mathrm{SJ}}(t)=U_{\max } \sin (\omega t)\right.$, where $\omega=2 \pi f, U_{\max }$ is the velocity amplitude, and $f$ is the actuation frequency, $\left.f=1 / T\right)$, we can derive the following form of $c_{m}$ :

$$
c_{m}=n\left(\frac{\pi}{2}\right)^{2}\left(\frac{A_{S J}}{A}\right)\left(\frac{U_{O S J}}{U_{0}}\right)^{2}
$$

It is worthy to note here that slightly different definition was used by Tamburello and Amitay [10], who used the momentum coefficient $c_{\mu}=\left(8 / \pi^{2}\right) c_{m}$.

The Strouhal number of the main jet is defined by frequency $f$ of SJ oscillation and diameter $D=10 \mathrm{~mm}$ of the main jet exit. Previous measurement [1] of the main jet set $U_{0}=2.5 \mathrm{~m} . \mathrm{s}^{-1}$.

$$
S t=\frac{f D}{U_{0}}
$$

For discrete experimental data simple time-average velocity was used:

$$
\bar{U}_{t a}=\frac{1}{n} \sum_{i=1}^{n} U_{i}
$$

where $n$ is the number of measurements in a set and $U_{i}$ means $i^{\text {th }}$ measured value. 
Phase-averaging of a periodic action is done using an arithmetic average of the corresponding points from many periods, i.e. points with the same phase shift in every period. In the case of discrete experimental data of instantaneous velocity, the phaseaverage component of the velocity is defined:

$$
\bar{U}_{p a}(\varphi)=\frac{1}{p} \sum_{i=1}^{p} U_{i}(\varphi),
$$

where $U_{i}(\varphi)$ is instantaneous velocity measured in $i^{\text {th }}$ period with phase shift $\varphi$, and $p$ is the number of processed periods.

For the Particle Image Velocimetry (PIV) measurement, the double pulse Nd:YAG laser and digital CCD camera with a spatial resolution of $1280 \times 1024$ pixels was used; both produced by Dantec Dynamics. Olive-oil seeding particles were generated by the Scitek LS-10 generator. By the synchronization of PIV system and SJ actuators, 100 image pairs were acquired at the same phase of the cycle. These images were processed by crosscorrelation (interrogation area $32 \times 32$ pixels, overlap 50\%); range validation and vector statistics were done by the DynamicStudio software. The velocity uncertainty was estimated to be $1,25 \%$.

Hot-wire experiments were carried out using a DANTEC anemometer MiniCTA with 55P16 single-wire probe, operating in the Constant Temperature Anemometry (CTA) mode. The sampling frequency was set to $10 \mathrm{kHz}$, and the typical number of samples was 32768 or 131072. For the present experiments, the anemometer was calibrated in the velocity range from 0.17 to $62 \mathrm{~m} . \mathrm{s}^{-1}$; the linearization error of the calibration (using a fifthdegree polynomial) was within $6 \%$, and the velocity sample uncertainty was estimated to be within $7 \%$.

\section{FREQUENCY CHARACTERISTIC OF SINGLE SYNTHETIC JET}

Frequency characteristic was measured both on new made segment and original complete jet. In the case $(A)$ the segment was supplied by loudspeaker $\mathrm{Nr} .3$ (power input $0.01 \mathrm{~W}$ ) and series-connected with loudspeaker $\mathrm{Nr}$. 4 (power input $0.01 \mathrm{~W}$ ) that was placed out of the measured flow field so that the loading of amplifier was identical with case (B). In the case (B) the loudspeakers were connected in phase opposition. This means that in the same time the air is sucked into the cavity of one generator and extruded from the other generator. Overview of $(A)$ and $(B)$ cases is summarized in Table 1.

Table 1: Parameters of CTA measurement of the single S]

\begin{tabular}{cccccc} 
& & \multicolumn{2}{c}{ position of the anemometer $\left(z^{*}=0\right)$} & loudspeakers & power input \\
Case & generator & $x^{* *}(\mathrm{~mm})$ & $y^{*}(\mathrm{~mm})$ & Nr. & $P(\mathrm{~W})$ \\
\hline \hline (A) & segment & 1,5 & 0 & $3(+4)$ & $0,01(+0,01)$ \\
(B) & complete jet & 1,5 & 0 & $3+4$ & $0,01+0,01$
\end{tabular}

First, the frequency characteristic on segment (A) and complete jet was measured, see Figure 2. Time-mean velocities according to equation (9) are displayed. The resonance was find at the frequency of $30 \mathrm{~Hz}$ for both cases (A) and (B). After that the velocity falls, whereas in the ranges of $60-80 \mathrm{~Hz}(A)$ and $70-100 \mathrm{~Hz}(B)$ is the velocity somewhere constant. Then the decrease is continuing so that over $f>120 \mathrm{~Hz}$ where the synthetic jet 
is very weak or it even does not exist (case (B) or (A), respectively). Maximal time-mean velocity measured on segment and complete jet differs. The difference is $60 \%$ at the resonance frequency and with higher frequency becomes bigger, whereas velocity from the complete jet is always higher. These differences could be caused by segment geometry deviations (inaccuracy of the exit slot and internal structure, connection to the cavity with membrane of the loudspeaker with different pipes) and then by spatial arrangement of experiment when the opposite placed jet are affected.

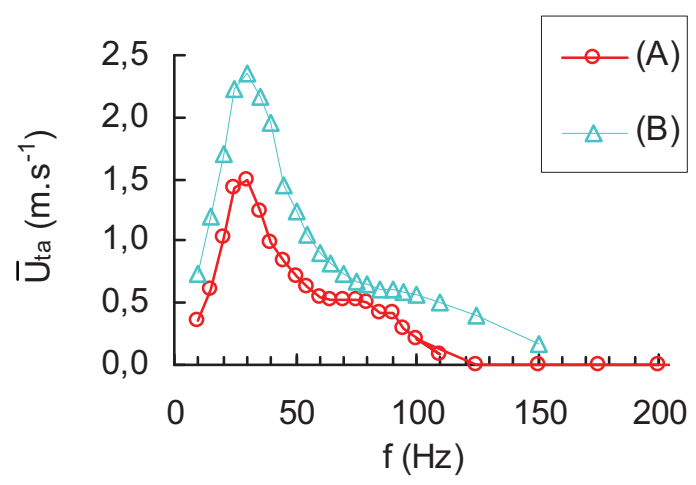

Figure 2: Frequency characteristic of segment $(A)$ and complete jet (B)

CTA measurements of velocity profiles were performed for the single SJ, i.e. SJ generated from the segment (see Figure 1(b)). The results are shown in Figure 3 (some of these results were already published - Trávníček et al. [7]). The presumption relating to the jet deflection from the $\mathrm{x}^{* *}$ axis is well confirmed.

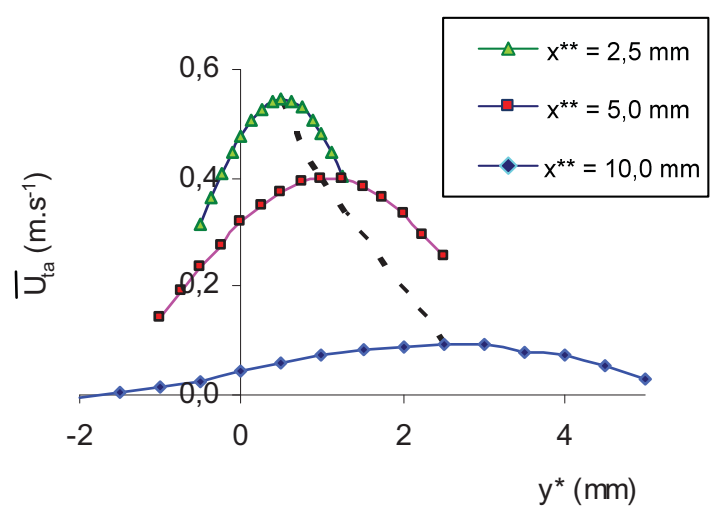

(a)

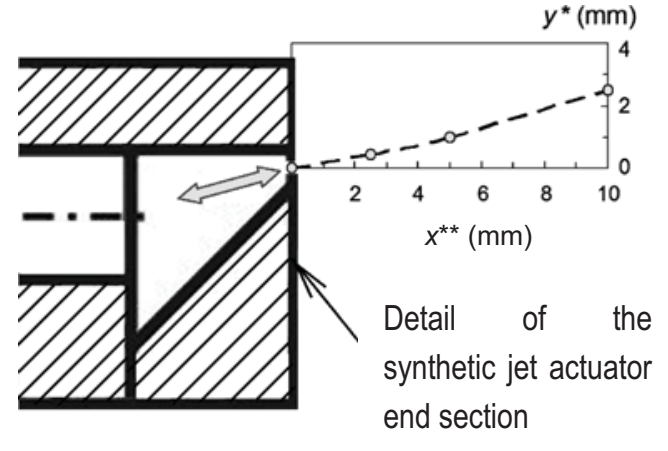

(b)

Figure 3: (a) Velocity profiles of synthetic jet at distances $x^{* *}=2,5$; 5 a $10 \mathrm{~mm}$ and frequency $f=81 \mathrm{~Hz}$; (b) Detail of the synthetic jet end section - deflection of the synthetic jet from the $x^{* *}$ axis

PIV measurement near the SJs orifices with the complete nozzle (Figure 1(a)) is extremely difficult, because geometry complicates an access of the laser beam to the SJ exit. That is the reason why PIV measurements were performed on the segment, see Figure 1(b). PIV measurements were conducted on the deflected axis $x^{*}$. Following CTA measurements, three frequencies for PIV experiments were selected $-30 \mathrm{~Hz}, 81 \mathrm{~Hz}$, and $190 \mathrm{~Hz}$. 


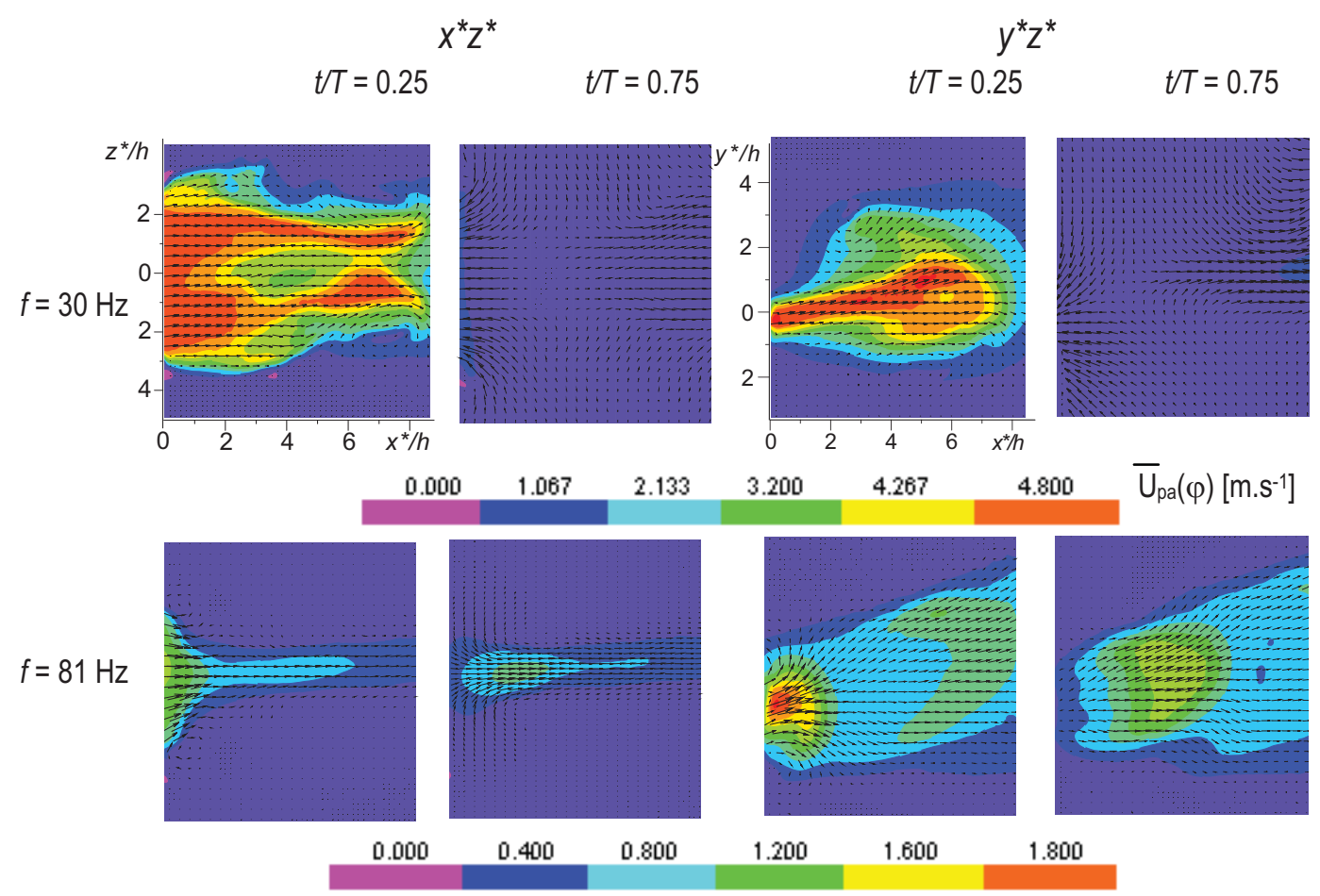

$f=190 \mathrm{~Hz}$

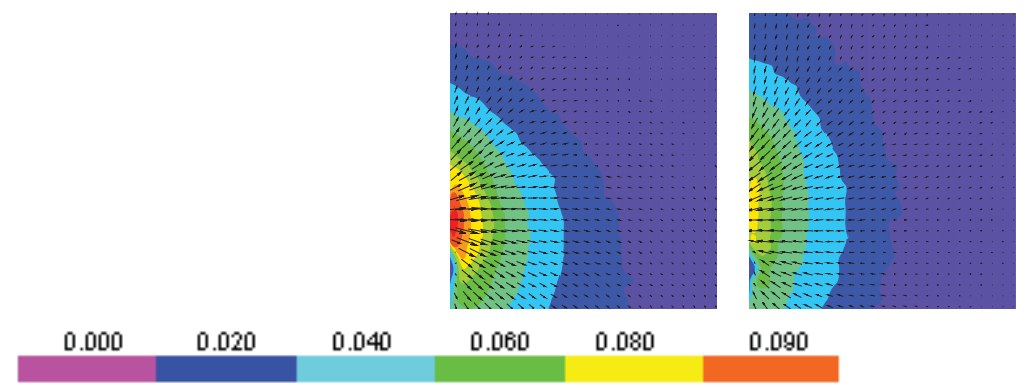

(a)

(b)

Figure 4: Synthetic jet at maximal velocities of extrusion $(t / T=0.25)$ and suction $(t / T=0.75)$ in the (a) $x^{*} z^{*}$ and (b) $y^{*} z^{*}$ plane, at frequencies of $f=30 \mathrm{~Hz}, 81 \mathrm{~Hz}$ and $190 \mathrm{~Hz}$.

Figure 4 shows a comparison of SJ velocities at extrusion $(t / T=0.25)$ and suction $(t / T=0.75)$ strokes at chosen frequencies in $x^{*} z^{*}$ and $x^{*} y^{*}$ planes. There is an appreciable difference in the character of the jet at $f=30 \mathrm{~Hz}$ and $81 \mathrm{~Hz}$. At the lower frequency, the jet is wider ( $4 h$ in the distance of $x^{*} / h=6$ ) and faster - $\max 4.8 \mathrm{~m} \cdot \mathrm{s}^{-1}$. In the first quarter of the cycle, the extruded air reaches to the distance of $x^{*} / h=8$. At the jet edges, two counter rotating vortices are developed. The jet is divided into two legs (at the distance of $x^{*} / h=2$ ); more downstream, they are pushed back together by the boundary vortices. This marked three-dimensional effect is known as the "axisswitching" of the jet. This effect can lead even to separation of the vortex structure into two parallel legs - see e.g. Husain and Hussain [8] and Fischer et al. [9]. In the other half of the cycle is the previous jet off and the suction can be proceed in the whole length of the slot.

At higher frequency $f=81 \mathrm{~Hz}$, in the first quarter of the cycle, the extruded air is located close to the jet exit. The maximal velocity is $1.8 \mathrm{~m} . \mathrm{s}^{-1}$. The extruded air is moved slower, 
and therefore it cannot leave the area at the jet exit during the suction stroke. Figure 4 shows SJ at frequency of $190 \mathrm{~Hz}$ too, for comparison purposes. SJ velocity is very small, maximal $0.090 \mathrm{~m}^{-\mathrm{s}^{-1}}$. SJ is not generated. This is in a good agreement with thermoanemometric measurements of frequency characteristic of the synthetic jet, when jet velocities are negligible at frequencies higher then $120 \mathrm{~Hz}$. Air movements caused by oscillating membrane are noticeable only close to the jet exit during the whole cycle compare to synthetic jet generated with $30 \mathrm{~Hz}$ that leaves the investigated area.

Examples of a round air jet actively controlled using a system of four synthetic jet are shown in Figure 5. This problem were investigated e.g. in Pírková et al. [5, 6, 11]. For this case, velocity, flow rate and momentum coefficients are: $c_{U}=0.17, c_{Q}=0.056[(5 a)$ and (5d)] or $0.028\left[(5 b)\right.$ and (5c)] and $c_{m}=0.023[(5 a)$ and (5d)] or $0.011[(5 b)$ and (5c)]. The rather small values of $c_{Q}$ and $c_{m}$ demonstrate a good efficiency of the present control mechanism. Note that the value of $c_{m}$ is in a reasonable agreement with Tamburello and Amitay [10], who used a single S] for vectoring of a round air jet at $c_{\mathrm{m}}=0.006-0.20$.

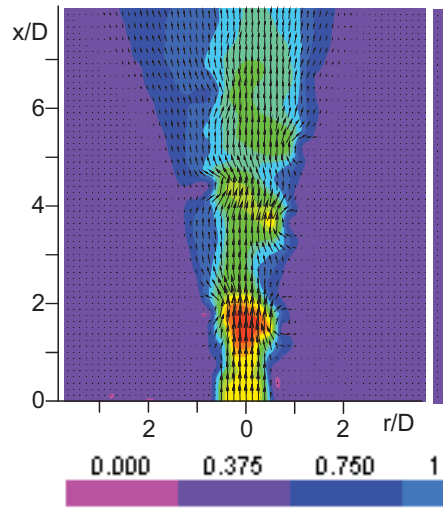

(a)

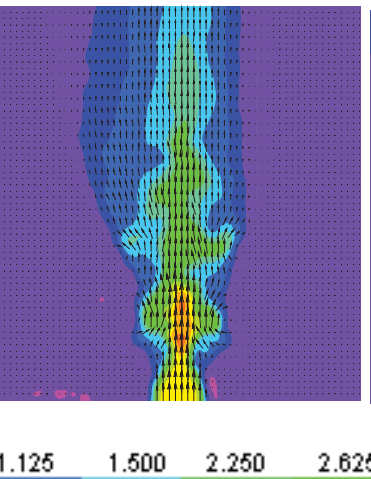

(b)

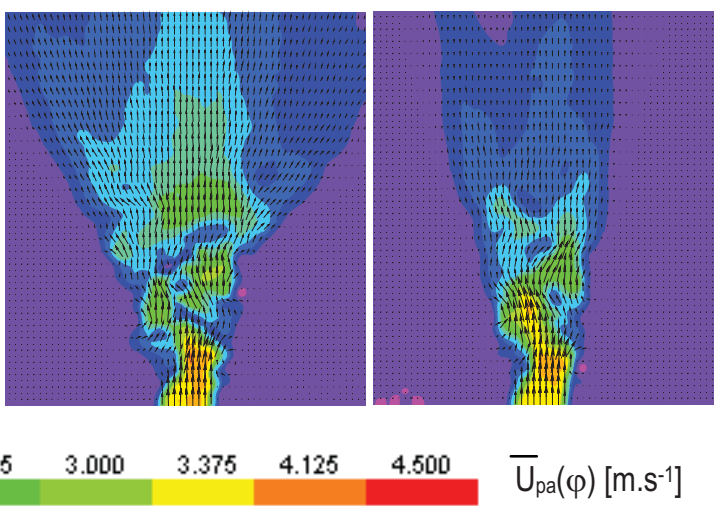

(c) (d)

Figure 5: Examples of actively controlled round air jet $(R e=1600, S t=0.32)$ using synthetic jets $(f=81 \mathrm{~Hz})$ in different modes: (a) axisymmetric, (b) plane symmetric, (c) bifurcated and (d) helical.

\section{CONCLUSION}

It was experimentally confirmed that the behaviour of a synthetic jet generated from a single segment actuator is acceptably close to the behaviour of four control synthetic jets that are generated from the complete nozzle. The resonance is found in both cases in the area of low frequencies of $30 \mathrm{~Hz}$, see Figure 2. In this case, the synthetic jet is generated in the range of frequencies from $10 \mathrm{~Hz}$ to $120 \mathrm{~Hz}$ - CTA and PIV measurements are here in a good agreement. At the frequency of $30 \mathrm{~Hz}$, an interesting three-dimensional effect of the "jet axis switching" $[8,9]$ has been found.

In the previous work $[5,6]$, it was stated that even very weak synthetic jets at frequencies higher than $120 \mathrm{~Hz}$ can control the round air jet. In this work, we found that the synthetic jet is not generated for $f>120 \mathrm{~Hz}$, thus the control effect is caused by an acoustic excitation instead of an interaction of two flows as at lower frequencies. 
An example of the control effect on the round air jet ( $S t=0.32, R e=1600$ ) was presented. In this case the momentum coefficient is $c_{m}=0.023$ for axisymmetric and helical mode and $c_{\mathrm{m}}=0.011$ for plane symmetric and bifurcated mode. The rather small values of $c_{\mathrm{Q}}$ and $c_{\mathrm{m}}$ indicate a good efficiency of the present flow control arrangement. Moreover, the value of $c_{m}$ is in a reasonable agreement with the experimental studies by Tamburello and Amitay [10], who successfully vectored a round air jet by a single synthetic jet at the range $c_{m}=0.006-0.20$.

Detailed investigation of a single synthetic jet contributes to a revelation of suitable parameters (the Strouhal and Reynolds numbers, and the momentum coefficient) for required control effect of synthetic jets on the main jet. This will be useful for the future experimental investigation aiming on design of the actuators for a more effective flow control.

\section{Acknowledgement}

We gratefully acknowledge the support of the Grant Agency CR (102/08/H08), the support of the Research Centre TEXTIL II (1M0553) and the Grant Agency of CR - Czech Science Foundation (101/09/1959).

\section{REFERENCES}

[1] Gad-El-Hak M.: Interactive control of turbulent boundary layers - A futuristic overview, AIAA Journal 32 (9) (1994) 1753-1765.

[2] Fernholz H.H.: Management and control of turbulent shear flows, Zeitschrift fur angewandte Matematik und Mechanik, 73 (11) (1993) 287-300.

[3] Smith B.L., Glezer A.: The formation and evolution of synthetic jets, Phys. Fluids 10 (9) (1998) 2281-2297.

[4] Cater J.E., Soria J.: The evolution of round zero-net-mass-flux jets, J. Fluid Mech. 472 (2002) 167-200.

[5] Pírková L., Kopecký V., Trávníček Z.: Experimental and numerical study of a controlled pulsating flow, Conference on Structure and Structural Mechanics of Textile Fabrics, Liberec, 2008.

[6] Pírková L., Kopecký V., Trávníček Z.: PIV measurements of a round air jet excited into various modes, 11th International Scientific Seminar on Developments in Machinery Design and Control, Červený Klášter, Slovakia, 2007, pp. $71-72$.

[7] Trávníček Z., Němcová L., Kordík J., Tesař V., Kopecký V.: Axisymmetric impinging jet excited by a synthetic jet system, International Journal of Heat and Mass Transfer, (2011, accepted for publication).

[8] Husain H.S., Hussain F.: The elliptic whistler jet, J. Fluid Mech. 397 (1999) 23 44.

[9] Fischer C., Sharma R.N., Mallinson G.D: Flow visualisation to identify mechanisms leading to axis-switching of slotted synthetic jets, 17th Australasian Fluid Mechanics Conference, Auckland, New Zealand (2010).

[10] Tamburello D. A., Amitay M., Three-dimensional interactions of a free jet with a perpendicular synthetic jet, Journal of Turbulence, vol. 8 (38) (2007).

[11] Pírková L., Kopecký V., Trávníček Z., PIV studium kontinuální trysky řízené pulzujícími proudy (PIV study of a continual jet controlled by pulse jets). Strojárstvo, June 2009, 206-208. 